\title{
SME NETWORK CHARACTERISTICS VS. PRODUCT INNOVATIVENESS: HOW TO ACHIEVE HIGH INNOVATION PERFORMANCE
}

\begin{abstract}
Small and medium sized enterprises (SMEs) must on the one hand innovate for company survival with the appropriate degree of product innovativeness, and on the other hand they need to collaborate and focus on core competences for efficiency matters. This research examines the relation of network characteristics and product innovativeness on innovation performance in SMEs. We tested hypotheses on the relationship between these three variables via data gathered from 60 SMEs, active in the medical devices sector. In this context we aim to offer consensus in the theoretical and empirical question of whether or not network characteristics and product innovativeness have a direct effect on innovation performance of SMEs.

Results show no significant direct effect of product innovativeness on innovation performance. A positive interaction effect of multiple network characteristics on innovation performance was found. Which confirms the significant importance of network configuration on innovation performance for SMEs. It indicates that, for SMEs in a highly regulated sector like the medical devices sector, the interaction of network characteristics is of crucial importance for high innovation performance. It is the combination of network characteristics that counts.
\end{abstract}

Key words: Innovation performance, Network characteristics, Product Innovativeness, SMEs 


\section{INTRODUCTION}

Given the importance of innovation and new product development for company survival it is not surprising that many companies desperately seek to improve their innovation performance. Especially small and medium sized enterprises (SMEs $\left.{ }^{1}\right)$ encounter difficulties in their NPD process due to a lack of financial resources and a lack of manpower (Kaufmann \& Tödtling, 2002). For efficiency matters these companies need to focus on their core competences (Penrose, 1959). This focus on core competences inherently means that SMEs cannot do everything themselves and therefore they need to cooperate in new product development (Hanna \& Walsh, 2002; Karlsson \& Olsson, 1998; MacPherson, 1997; Rogers, 2004; Rothwell, 1991). By using interorganizational relationships the "burden" of innovation can be shared between several organizations (Ritter \& Gemünden, 2003).

The more firms engage in a variety of different inter-organizational collaborations (i.e. the more they interact with external partners), the more likely they are to create new or improved products that are commercially successful (Faems, VanLooy, \& Debackere, 2005). successful commercialization of technology often requires collaboration among horizontal competitors that have different capabilities (Teece, 1989). More recently there is a shift from vertical integration (which decreases) to more informal arrangements that keep industrial networks together (Gadde \& Håkansson, 1994). Especially in the field of new product development networking activity becomes more and more popular as cooperation with other organizations increases the innovation performance of organizations (Chang, 2003; Groen, Wakkee, \& DeWeerd-Nederhof, 2008; Håkansson, 1987; Hanna \& Walsh, 2002; Pittaway, Robertson, Munir, Denyer, \& Neely, 2004; Ritter \& Gemünden, 2003, 2004; Rothwell, 1991; Salman \& Saives, 2005). The innovation benefits of networking Pittaway et al (2004) identify include:

\footnotetext{
${ }^{1}$ According to European standards, SMEs are defined as companies that have 250 or fewer fulltime employees (Commission of the European Communities. 2003. Commission Recommendation of 6 May 2003 Concerning the Definition of Micro, Small and Medium-Sized Enterprises (notified under document number C (2003) 1422) 2003/362/EC., Vol. 46 (L124): 36-42: Official Journal of the European Union.)
} 
1) risk sharing, 2) obtaining access to new markets and technologies, 3) speeding products to market, 4) pooling complementary skills, 5) safeguarding property rights when complete or contingent contracts are not possible, and 6) acting as a key vehicle for obtaining access to external knowledge (Pittaway et al., 2004).

Nieto and Santamaría (2010) find that technological collaboration is a useful mechanism for firms of all sizes to improve innovation performance. It is, however, a critical factor for small firms. They find that collaboration contributes to improving the innovation performance of SMEs (Nieto \& Santamaría, 2010). Nooteboom (1994) argues that 1) small firms have potentially more to gain from innovative partnerships than larger firms, and 2) that small and large firms are probably good at different innovativeness types of innovation in accordance with their relative strengths and weaknesses (Nooteboom, 1994). Product innovativeness (i.e. the level of newness of the product to the market and the firm (Booz, Allen, \& Hamilton, 1982; Langerak \& Hultink, 2006)) is an important classifier of new products reflecting a choice, either explicit or implicit, of product strategies (Song \& Montoya-Weiss, 1998). It is assumed to be an important moderating or control variable in relationships between organizational characteristics and innovation performance, because the level of resources and the mix of organizational characteristics varies between different levels of product innovativeness (Wheelwright \& Clark, 1992). This argument has been proved to be correct for internal organizational characteristics in relation to innovation performance (Danneels \& Kleinschmidt, 2001; Kleinschmidt \& Cooper, 1991; Langerak \& Hultink, 2006; Szymanski, Kroff, \& Troy, 2007). However, the role of product innovativeness in the relation between network characteristics and innovation performance is not thoroughly examined.

The research question we are trying to answer in this research is to what extent network characteristics and product innovativeness are directly related to innovation performance in the context of SMEs. The objective is to examine the underlying structure of network 
characteristics, innovation performance and product innovativeness to be able to improve the innovation performance of SMEs and to offer consensus in the theoretical and empirical question of whether or not product innovativeness and network characteristics have direct effects on innovation performance.

As suggested by Langerak and Hultink (2006) we conducted a single-industry study to rule out possible confounding effects due to unmeasured industry level factors (Langerak \& Hultink, 2006). The industry we selected to conduct the research in is the medical devices industry, because collaboration with external partners for new product development becomes increasingly important due to the complexity of the products and the fragmentation of the market. In their study on success factors for medical devices SMEs in the UK Hourd and Williams (2008) found that all their case companies had established collaborations throughout the value chain in order to provide the skills, competencies, and sometimes investment in (among others) the area of new product development (Hourd \& Williams, 2008). Furthermore, due to the strict regulations the level of product innovativeness is a relevant issue in new product development (Atun, Shah, \& Bosanquet, 2002; Kaplan et al., 2004). The average development time for medical devices ranges from 1-2 years for incremental devices and 5-7 years for radical devices, dependent on the product type, complexity, and degree of risk to the patient that dictates their regulatory defined conformance and approval route (Hourd \& Williams, 2008).

To answer our main research question "to what extent are network characteristics, product innovativeness, and innovation performance related?" we construct a number of theory-based hypotheses in the first section of this paper. In the methodology section we elaborate on the research context of the medical devices sector, the data gathering process and sample, the 
operationalization of variables and the research method of multiple logistic regression. Subsequently, we present and discuss the research results and give concluding remarks.

\section{BUILDING HYPOTHESES ON NETWORK CHARACTERISTICS, PRODUCT INNOVATIVENESS AND INNOVATION PERFORMANCE}

The theoretical framework as described in this section covers literature on the relation between network characteristics and innovation performance and on the relation between product innovativeness and innovation performance. In addition, based on literature three research hypotheses are constructed in this section.

In this research the definition of innovation proposed by Afuah (1998) is used, who states that in the field of high technology innovation is invention + commercialization (Afuah, 1998). The performance that is achieved as a results of new product development is the innovation performance (Salomo, Strecker, \& Talke, 2007).

\section{Theroretical Embeddedness of the Research}

One of the first lines of theory development which stressed the role of interaction patterns between actors to explain the sustainability of a social system as a reaction against the too atomistic classical economic theories was developed in the social systems perspective by Talcott Parsons (Parsons, 1937, 1964). The assumption of the importance of relationships among interacting units is further developed in structural network theory (Wasserman \& Faust, 1994). In strategic management Child followed up in this acknowledging the presence of strategic choice (Child, 1972) which implies that organizations are not always passive recipients of environmental influence but also have the power to reshape the environment. The focus of the network dimension of the social systems perspective is on relationships 
among social entities, and on the patterns and implications of these relationships In the social systems perspective the interaction between actors in an external environment is what adds value (Aldrich \& Pfeffer, 1976; Wasserman \& Faust, 1994).

The theoretical framework is inspired by the social systems perspective (Parsons, 1964) and the multidimensional framework of Groen et al. (2008) which inhibits the structural, relational and cognitive dimension that Nahapiet and Goshal (1997) distinguish. In addition a fourth dimension "Economic capital" is included (see Figure 1). In the framework of Groen et al. (2008) it is assumed, that each of the four dimensions of the social system produces its own type of capital: social capital (related to the structural dimension), strategic capital (related to the cognitive dimension), economic capital and cultural capital (related to the relational dimension). Sufficient capital is needed on each of the four dimensions to create sustainable enterprises (Groen et al., 2008)

Insert Figure 1 about here.

\section{Network Characteristics in relation to Innovation Performance}

An in-depth literature review indicated that the network characteristics "Goal Complementarity" (relates to strategic capital), "Resource Complementarity" (relates to economic capital), "Trust" (relates to cultural capital), and "Network Position Strength" (relates to social capital) are most closely related to innovation performance for SMEs in the medical devices sector (Pullen, Groen, Fisscher, \& De Weerd-Nederhof, 2010).

Prior research has frequently considered the effect of these network characteristics on innovation performance. For example, Bourgeois III (1980) concludes that a coalition of strategy makers cannot focus on alternative means without a clearly conceived set of goals in mind (Bourgeois III, 1980). Value, in terms of innovation performance, can be created 
through cooperation and knowledge sharing (Inkpen \& Tsang, 2005). When the objectives and strategies of an alliance are clearly stated, a foundation of common understanding and the means to achieve the collaborative purpose is established among the partners.

Further, in relationships between companies the physical and organizational resources of the company are exchanged and combined with those of its counterparts in order to achieve the set goals (Haythornthwaite, 1996; Tichy, Tushman, \& Fombrun, 1979). Lambe et al (2002) distinguish between resources that are developed and resources that are used in external collaboration: idiosyncratic and complementary resources (Lambe, Spekman, \& Hunt, 2002). Firms are encouraged to innovate by searching out new resources, or new ways of using existing resources, as the basis for future organizational rents (Galunic \& Rodan, 1998; Håkansson, 1989; Oerlemans, Meeus, \& Boekema, 1998).

Another important firm network characteristic is trust. Trust is necessary for people to work together on common projects, even if only to the extent that all parties believe they will be compensated in full and on time (Leana \& Van Buren III, 1999). Trust is defined as the belief that the results of somebody's intended action will be appropriate from our point of view (Nahapiet \& Ghoshal, 1998) and is often the base for external cooperation. Earlier research indicated that trust comprises multiple facets. For instance, Faems et al (2008) distinguish between competence trust, which is defined as encompassing positive expectations about a partner's ability to perform according to an agreement, and goodwill trust, which is defined as the partner's intention to perform according to an agreement. They find that competence trust is a crucial condition for subsequent transactions and goodwill trust is found to be a condition that determines how contracts are applied (Faems, Janssens, Madhok, \& Van Looy, 2008). In addition, Zaheer et al. (1998) distinguish between fairness, reliability and predictability as facets of trust. More recent Gulati and Sytch (2008) investigated the formation of trust between firms. To measure trust, they adapted the trust measures of Zaheer et al. (1998). 
Empirical testing of the trust measure of Gulati and Sytch indicated that trust is twodimensional (Pullen et al., 2010). These two dimensions are fairness trust and reliability trust. Fairness trust considers the expectation that an actor will act and negotiate fairly. Reliability trust considers the expectation that an actor can be relied upon to fulfill obligations (Gulati \& Sytch, 2008; Zaheer, McEvily, \& Perrone, 1998).

Network position strength considers the structure of the network. The structure of the network is on the one hand based on the combination of contacts a company has in relation to contacts that other companies have (Groen et al., 2008) and on the other hand on the strength of a company's network position. This determines to a great extent its access to knowledge and other resources that are necessary for successful product development. The extensive body of literature concerning network characteristics repeatedly indicates the importance of the structure of the network in terms of the presence of structural holes (Burt, 1992; Haythornthwaite, 1996) and the density of the network (Borgatti, Jones, \& Everett, 1998; Burt, 1992; Gilsing \& Nooteboom, 2005) in relation to innovation performance. These items are captured in the network characteristic network position strength (Pullen et al., 2010). Based on the above literature our first set of hypotheses hypothesis is :

Hla. The higher the level of goal complementarity, the higher the innovation performance of the SME.

H1b. The higher the level of resource complementarity, the higher the innovation performance of the SME.

H1c. The higher the level of fairness trust, the higher the innovation performance of the SME. 
HId. The higher the level of reliability trust, the higher the innovation performance of the SME.

Hle. The higher the level of network position strength, the higher the innovation performance of the SME.

The focus on one or more network characteristics in solitude in relation to innovation performance leads to a form of reductionism (Van de Ven \& Drazin, 1985), as 1) real-life organizations and networks consist of multiple characteristics in combination, and 2) the interaction between the variables is ignored which might lead to different research results. This form of reductionism can be overcome by addressing the characteristics of organizations in combination (Miller \& Friesen, 1982). As Van de Ven and Drazin (1985) state: "Only by simultaneously addressing the multiple characteristics of organizations can relationships between performance and these organizational characteristics be fully understood" (Van de Ven \& Drazin, 1985). The network characteristics in combination, or in other words the network configuration, must be taken into account when analyzing technological networks. This result is important for managerial day-to-day decision making too (Gemünden, Ritter, \& Heydebreck, 1996).

According to Nahapiet and Ghoshal (1997) the structural dimension (social capital) may stimulate both the relational (cultural capital) and cognitive (strategic) dimension, since the location of an actor's contacts in a social structure of interactions provides certain advantages for the actor. In addition, social interaction plays a critical role in shaping a common set of goals and values (Nahapiet \& Ghoshal, 1997). In terms of the network characteristics of this research this means that the interaction between network position strength and the other 
network characteristics is related to high innovation performance. This brings us to the second set of hypotheses.

H2a. The interaction between network position strength and goal complementarity is positively related to innovation performance.

H2b. The interaction between network position strength and resource complementarity is positively related to innovation performance.

H2c. The interaction between network position strength and fairness trust is positively related to innovation performance.

H2d. The interaction between network position strength and reliability trust is positively related to innovation performance.

\section{Product Innovativeness in relation to Innovation Performance}

Product innovativeness is defined as the extent to which a product is new to the target market and to the developing firm (Langerak \& Hultink, 2006). Booz, Allen and Hamilton (1982) categorize new products along two dimension: newness to the developing firm and newness to the market. In their typology they distinguish between six types of new products: new-to-theworld products, new product lines, additions to existing product lines, repositionings, improvements/ revisions to existing products, and cost reductions (Booz et al., 1982).

The relation between product innovativeness and innovation performance has been studied extensively in prior research. An important contribution in this field was made by Kleinschmidt and Cooper (1991) and Wheelwright and Clark 1992). Kleinschmidt and 
Cooper (1991) find that low and highly innovative new products tend to be more successful than moderately innovative new products (Kleinschmidt \& Cooper, 1991). Wheelwright and Clark (1992) also distinguish in product innovativeness as they state that the level of resources and the mix of organizational characteristics (the pattern) is different for radical and incremental innovation (Wheelwright \& Clark, 1992). Both Kleinschmidt and Cooper (1991) and Wheelwright and Clark (1992) imply a direct relation between product innovativeness and innovation performance.

More recently, Danneels and Kleinschmidt (2001) conducted an extensive literature review on the role of product innovativeness on firm performance. In empirically testing the proposed dimensions of product innovativeness from the firm's perspective and their relation with new product outcomes they use the typology of Booz, Allen and Hamilton (1982). Product innovativeness is found to have the role of independent variable and is found to have a direct effect on innovation performance (Danneels \& Kleinschmidt, 2001). This direct relation has also been found in the research of Szymanski et al (2007). They find a direct relationship between product innovativeness and performance but since this effect explains only $5 \%$ of the variance across correlations it suggests that there are other factors that exert a significant main effect on new product performance (Szymanski et al., 2007).

Even though examined thoroughly I prior research, the relation between product innovativeness and innovation performance has not yet been studied in the context of interorganizational NPD. However, since organizational boundaries are blurring and network characteristics are part of the organizational characteristics in general, a direct relation between product innovativeness and innovation performance in the context of interorganizational NPD is expected to be found. In the setting of SMEs in the medical devices sector we hypothesize a negative direct relation, as the strict sector regulations make 
it difficult for companies to commercialize radically new products. Therefore, the third hypothesis is:

H3. The lower the level of product innovativeness, the lower the innovation performance for SMEs in the medical devices sector.

The variables and their hypothesized relations are visualized in the research model below.

Insert Figure 2 about here

\section{TOWARDS A RESEARCH APPROACH}

This methodology section first explains more in-depth why the medical devices sector was selected as research context (\$3.1). Second, it describes the sampling and data gathering process (\$3.2). $\$ 3.3$ describes the operationalization of variables and tests the validity of the self-administered questionnaire. The research method of multiple logistic regression is described in $\S 3.4$.

\section{The Medical Devices Sector as Research Context}

A suitable context for this research inhibits a sector in which high levels of collaboration and NPD activity are present and which is dominated by SMEs. A sector that meets these requirements is the medical devices sector ${ }^{2}$.

The medical devices sector is characterized by very strict regulations (Kaplan et al., 2004). Both the quality and safety of products are very important and guaranteed by very strict

\footnotetext{
${ }^{2}$ According to medical device directive 93/42/EEC, a medical device is:”... any instrument, apparatus, appliance, material, or other article, whether used alone or in combination, including the software necessary for its proper application, intended by the manufacturer to be used for human beings for the purpose of a) Diagnosis, prevention, monitoring, treatment or alleviation of a disease, b)Diagnosis, monitoring, treatment or alleviation of or compensation for an injury or handicap, c)Investigation or modification of the anatomy or of a physiological process, or, d)Control of conception. And which does not achieve its principal intended action in or on the human body by a) Pharmacological, b)Immunological or c) Metabolic means, but which may be assisted in its function by such means".
} 
regulations that vary in their strictness based on the innovativeness of the newly developed product. These regulations are the cause of the time and cost consuming product development process (Atun et al., 2002). Unfortunately many product concepts are not being approved by these clinical trials and in doing so do not meet the regulations which means that the product may not be produced and commercialized (Shaw, 1998) (FDA, 2004). Mainly due to these regulations which cause a very time- and cost consuming new product development process (Kaplan et al., 2004; Nieto \& Santamaría, 2010) SMEs in the medical devices sector face the problem of a lack of financial resources and a lack of qualified personnel in their NPD process which makes it necessary for them to cooperate (Kaufmann \& Tödtling, 2002; Rogers, 2004). This need for collaboration becomes increasingly important due to the complexity of the products and the fragmentation of the market. $80 \%$ of the companies in this sector are SMEs and based on theory and in line with earlier research we assume that they need to cooperate with external partners to share resources for the development of new products (Biemans, 1989; Millson \& Wilemon, 2000; Prabhakar, 2006).

Furthermore, the intense competition, high rate of growth, continuing technological innovation, and customer sophistication suggest a significantly above average level of new product development activity (Rochford \& Rudelius, 1997).

\section{Data Gathering and Sample}

Through a telephone pre-survey among 751 Dutch medical devices companies, companies that actively participate in the development of new medical devices and that have less than or equal to 250 Full Time Equivalents were identified as suitable companies to participate in the research. In this telephone pre-survey also key respondents were identified, the purpose of the research was explained and the potential respondents were asked to participate in the research. A total of 105 suitable companies were identified. A total of 97 potential respondents 
indicated that they were willing to cooperate with the research. They received a personalized letter explaining the purpose of the study, along with a questionnaire by e-mail. The questionnaire could be filled-in electronically and returned by e-mail. Non-respondents received reminder telephone calls and a second questionnaire. As respondent, the manager responsible for NPD in the specific organization or the manager who has been involved in the overall NPD program in the organization was selected. These efforts yielded 60 usable responses, giving a response rate of $61,9 \%$ percent which is $57,1 \%$ percent of the population of Dutch small-and medium sized medical devices companies with an NPD department (see Tables 1 and 2).

Insert Table 1 about here.

Insert Table 2 about here.

\section{Operationalization of Innovation Performance, Network Characteristics and Product}

\section{Innovativeness}

To examine the underlying structure of the different network characteristics and innovation performance we conducted factor analysis. An exploratory factor analysis was conducted because the measures for structure related network characteristics were not directly extracted from earlier research. In addition none of the measures were earlier combined into one survey. For both independent and dependent variables principal component analyses (PCA) were conducted (see Tables 3 and 4).

\section{Innovation performance}

From factor analysis it was found that innovation performance is represented by one factor that consists of 5 items. The factor has high reliability as the Cronbach's $\alpha=0,923$ and 
explains $76,5 \%$ of the variance (see Table 3). This measure is originally developed by Atuahene-Gima, Slater and Olsen (2005). To improve the goodness of fit of the model the factor scores of innovation performance were divided in three categories: 1) low, 2) medium, and 3) high:

1. Low: the innovation performance score is lower than the mean innovation performance score of the sample minus the standard deviation.

Low: score $\leq$ (mean score - stdev)

2. Medium: the innovation performance score is higher than the mean innovation performance score of the sample minus the standard deviation, but lower than the mean innovation performance score of the sample plus the standard deviation.

Medium: (mean score - stdev $)<$ score $<($ mean score + stdev $)$

3. High: the innovation performance score is higher than the mean innovation performance score of the sample plus the standard deviation.

High: score $\geq($ mean score + stdev $)$

Insert Table 3 about here.

\section{Network characteristics}

Factor analysis on the network characteristics indicated that the items in the questionnaire together build five constructs that together explain $76,38 \%$ of the variance. Items with loadings greater than 0,40 on a factor are considered significant. As can be seen in Table 4 there are three items (Q20.1, Q20.2 and Q20.3) that load on more than one factor. There is some disagreement in literature about what to do when items load on multiple factors. Kline (2000) suggests to drop the items that load on multiple factors, because they are difficult to interpret (Kline, 2000). However Hair et al. (1995) argues that the meaning of an item must be 
taken into account when assigning labels to a factor (Hair, Anderson, Tatham, \& Black, 1995). In line with Hair et al. (1995) Pett et al. (2003) suggest placing the item with the factor it is most closely related to conceptually instead of dropping the item. They argue that reliability tests of the factors will show the internal consistency of a factor and will also indicate whether or not reliability of a factor will increase by dropping an item (Pett, Lackey, \& Sullivan, 2003). As Hair et al. (1995) and Pett et al. (2003) we do not drop the items with multiple (significant) factor loadings, rather we assign the item to the factor it is most closely related to and use reliability test for internal consistency. All five constructs achieve high reliabilities, and high Eigenvalues (see Table 4).

Insert Table 4 about here.

\section{Product innovativeness}

To measure product innovativeness we use the Booz, Allen and Hamilton (1982) typology. Respondents are asked to mark the product innovativeness category that best describes their newly developed product. In our sample from medical devices SMEs only 3 companies marked their products as "new to the world" or "new product lines". All the other companies scored in the lower four quadrants of the Booz, Allen and Hamilton typology. To ensure that the number of cases per product innovativeness type is sufficient for data analyses, the 3 cases in "new to the world" and "new product lines" are excluded from the sample.

The companies in the sample (when "new to the world" and "new product lines" are excluded) are categorized in two groups based on the newness to the market (see figure 3). Group 1 includes the companies who indicated that their new developed product could be labeled as "improvement/ revision to existing products" or as "cost reductions". The products in this group have a low newness to the market in terms of Booz, Allen, and Hamilton (1982). 
Group 2 includes the companies who indicated that their newly developed product could be labeled as "addition to existing product lines" or as "repositioning". The products in this group have moderate newness to market. Group 2 is more market oriented that group 1 . These 2 groups of product innovativeness are used for data analysis.

Insert Figure 3 about here.

\section{Multiple Logistic Regression as Research Method}

An interaction approach based on Drazin and Van de Ven (1985) was used to test the hypotheses. The focus of this interaction approach is on explaining variations in organizational performance from the interaction of organizational structure and context (Drazin \& Van de Ven, 1985). The most common approach to the interaction test of fit consists of a series of two-way analyses of variance or regressions (Drazin \& Van de Ven, 1985).

Multiple logistic regression was conducted to examine the effect of the network characteristics goal complementarity, resource complementarity, fairness trust, reliability trust and network position strength, and product innovativeness on the categorical variable innovation performance. Not only the main effects of these variables were examined, also the interaction effect of the network characteristics in combination on the innovation performance was examined. To prevent multicollinearity we used the factor scores of the different network characteristics as independent variables in the multiple logistic regression. 


\section{RESULTS}

After the main effects were entered in model 0 of the multiple logistic regression. All 2-way, 3-way, 4-way, and 5-way interaction terms were entered in the successive models. Table 5 shows the amount of unexplained variability in the data in the original model and the final model (the result of the analysis). This difference $(\chi 2=45.447)$ is significant $(p<0.000)$ which indicates that the final model explains a significant amount of the original variability. In short, this model is better than no model or the original model.

Insert Table 5 about here.

The final model is not only significantly better than the original model, the final model is also a good fit of the data as shown in Table 6. The statistics are not significant which indicates that the predicted values are not significantly different from the observed values.

Insert Table 6 about here.

The specific effects of the predictors can be found in Table 7 which shows the individual parameter estimates. In Table 7 " $\mathrm{B}$ " represents the change in the logit of the outcome variable associated with a one-unit change in the predictor variable. The logit is the natural logarithm of the odds of Y occurring. More crucial to the interpretation of logistic regression is the value of the odds ratio " $\operatorname{Exp}(\mathrm{B})$ ". " $\operatorname{Exp}(\mathrm{B})$ " is the indicator of the change in odds resulting from a unit change in the predictor. It is similar to the B coefficient, but it doesn't require the logarithmic transformation. Therefore, we use the "Exp(B)" to interpret the results from Table 7.

Insert Table 7 about here. 


\section{Moving from Low to Medium Innovation Performance}

The first part of Table 7 shows the effects of network characteristics and product innovativeness on the increase from low to medium innovation performance. We included all two-way, three-way, four-way an five-way interaction effects in the model. However only interaction effects that led to significance of the regression model, are included in the final regression model. As Table 7 shows, there is no significant direct effect between product innovativeness and innovation performance. In addition also no direct significant effect was found between individual network characteristics and innovation performance, since the effects of individual network characteristics were eliminated from the model as they led to insignificance of the model. However the interaction between multiple network characteristics has a strong direct significant effect on increasing innovation performance.

The interaction between reliability trust and network position strength significantly $(\mathrm{p}<0.048)$ predicted whether medium or low innovation performance was achieved, $\mathrm{B}=1.875$, Wald $\chi 2(1)=3.900, \quad \mathrm{p}<0.048$. Which means that as the interaction term ReliabilityTrust*NetworkPositionStrength changes by one unit, the change in the odds (see column " $\operatorname{Exp}(B)$ " in Table 7) of achieving medium innovation performance compared to achieving low innovation performance is 6.523. In other words, the odds, when reliability trust and network position strength increase, of achieving medium innovation performance compared to low innovation performance is $1 / 6.523=0.15$ times more than when the values of reliability trust and network position strength do not increase.

The interaction between resource complementarity and network position strength significantly predicts whether medium or low innovation performance is achieved, $\mathrm{B}=-3.782$ Wald $\chi 2(1)=9.090, \mathrm{p}<0.003$. This means that when both these network characteristics change by 
one unit, the change in the odds (see column "Exp(B)" in Table 7) of achieving medium innovation performance compared to achieving low innovation performance is 0.023 . In other words the odds, when resource complementarity and network position strength both increase, of achieving medium innovation performance compared to low innovation performance is $1 / 0.023=43.48$ times more than when the values of resource complementarity and network position strength do not increase (see Figure 4).

Insert Figure 4 about here.

\section{Moving from Medium to High Innovation Performance}

The second part of Table 7 shows the effects of network characteristics and product innovativeness on the increase from low to high innovation performance. As Table 7 shows, again we found no direct significant effect of neither product innovativeness nor individual network characteristics on innovation performance. However, multiple interaction effects were found to have a direct effect on achieving high innovation performance.

The interaction between goal complementarity and network position strength significantly predicts whether high or low innovation performance is achieved, $\mathrm{B}=-3.458, \chi 2(1)=5.858$, $\mathrm{p}<0.016$. Which means that when these network characteristics change by one unit, the odds of achieving high innovation performance compared to achieving low innovation performance is 0.031 (see column "Exp(B)" in Table 7). So the odds, when the interaction term GoalComplementarity*NetworkPositionStrength increases, of achieving high innovation performance compared to low innovation performance is $1 / 0.031=32.26$ times more than when the interaction term does not increase.

Furthermore, the interaction between resource complementarity and network position strength significantly predicts whether high or low innovation performance is achieved $(\mathrm{B}=-3.126$, $\chi 2(1)=4.249, \mathrm{p}<0.039)$ as it also significantly predicted whether medium or low innovation 
performance is achieved. The odds, when the interaction term ResourceComplementarity*NetworkPositionStrength increases, of achieving high innovation performance compared to low innovation performance is $1 / 0.044=22.72$ times more than when the interaction term does not increase

Finally, the interaction between fairness trust and network position strength significantly predicts whether high or low innovation performance is achieved, $\mathrm{B}=-4.135$ Wald $\chi 2(1)=$ $1.808, \mathrm{p}<0.022$. When the interaction term changes by one unit, the change of the odds (see column "Exp(B)" in Table 7) of achieving high innovation performance compared to achieving low innovation performance is 0.631 . This indicates that the odds of achieving high innovation performance instead of low innovation performance increases by $1 / 0.016=62.50$ times when the values of the interaction term FairnessTrust*NetworkPositionStrength increase by one unit (see Figure 5).

Insert Figure 5 about here.

Hypotheses 1a-1e and hypotheses 2a-2d considered the relation between network characteristics and innovation performance. Hypotheses 1a through 1e stated that the higher the value of respectively "resource complementarity", "fairness trust", "network position strength", "reliability trust" and "goal complementarity", the high the innovation performance. None of the hypotheses from set 1 were supported, as no direct positive significant effects were found. Inclusion of these direct effect tests in the model, even led to insignificance of the regression model.

The most important results we found are related to hypothesis set 2. Hypotheses 2a through $2 \mathrm{~d}$ stated that the interaction between the network position strength and the other network characteristics has a direct positive effect on innovation performance. A number of significant 
2-way interaction effects between network characteristics on innovation performance were found to be significantly effective for increasing innovation performance. This supports hypotheses $2 \mathrm{a}$ through $2 \mathrm{~d}$ and indicates that the interaction between network characteristics is directly and positively related to innovation performance.

As can be seen from the models there is no direct negative effect of product innovativeness on innovation performance when shifting either from low to medium or from low to high innovation performance. Therefore, hypothesis 3 is rejected.

\section{DISCUSSION}

We began by observing that there is vast amount of research exploring the factors that influence or might influence the innovation performance among which network characteristics (Ahuja, 2000; Becker \& Dietz, 2004; Branzei \& Thornhill, 2006; Capaldo, 2007; Chang, 2003; Deeds \& Hill, 1996; Faems et al., 2005; Hillebrand \& Biemans, 2004; Powell, Koput, \& Smith-Doerr, 1996; Ritter \& Gemünden, 2003; Teece, 1989) and product innovativeness (Booz et al., 1982; Danneels \& Kleinschmidt, 2001; Kleinschmidt \& Cooper, 1991; Langerak \& Hultink, 2006; Rothwell, 1991; Salomo, Talke, \& Strecker, 2008; Szymanski et al., 2007). In the context of SMEs especially network characteristics and product innovativeness are of importance in relation to innovation performance as SMEs are bound by a lack of financial resources, manpower and substitutes for lack of sales (Hanna \& Walsh, 2002; Kaufmann \& Tödtling, 2002) in the new product development process. We examined the relation of network characteristic and product innovativeness on innovation performance.

One of the most telling result of our study concerns the fact that network characteristics in interaction have a direct positive effect on innovation performance. The significant interaction effect supports hypotheses $2 \mathrm{a}$ through $2 \mathrm{~d}$ and indicates the importance of viewing a 
company's external network characteristics in combination. Our findings show that, for SMEs in a highly regulated sector like the medical devices sector, the interaction of network characteristics is of crucial importance for high innovation performance. These findings support the argument of Van de Ven and Drazin (1985) that combinations of organizational (in this case network) characteristics need to be considered in order to fully understand its relation to performance. This aligns with configuration theory that posits that for each set of network characteristics, there exists an ideal set of organizational characteristics that yields superior performance (Van de Ven \& Drazin, 1985).

In addition, contrary to expectations, we found no direct negative (nor positive) relationship between product innovativeness and innovation performance. In the context of the interorganizational NPD for SMEs in the medical devices sector no direct relationship between product innovativeness and innovation performance was found, which provides new insights and adds to a better understanding of the relation of network characteristics and product innovativeness on innovation performance. Our findings are in line with the findings of Brown et al. (2008) who also find no statistically significant correlation between perceived success of the product and product innovativeness (Brown, Dixon, Eatock, Meenan, \& Young, 2008). One possible explanation for this lack of support is that our sample consisted of small and medium sized companies that were all active in the highly regulated medical devices sector (Atun et al., 2002; Kaplan et al., 2004). Since all companies in this sector must meet these strict product regulations we expect that companies rather focus on "safe" low and moderately innovative products rather than on "risky" highly innovative products. Another explanation might be that as Kleinschmidt and Cooper (1991), Wheelwright and Clark (1992), Langerak and Hultink (2006) and Gemünden et al (2007) confirmed in their research product innovativeness serves as a control variable. 


\section{LIMITATIONS AND FURTHER RESEARCH}

Our study has some limitations that suggest a number of directions for future research. We showed that the interaction between network characteristics (the network configuration) has a direct effect on innovation performance. As we focused on examining the relation of network characteristics and product innovativeness on innovation performance it was out of the scope of this research to examine the interaction between network characteristics within the configuration. Further research might focus on this interaction within network configurations. We agree with Pittaway et al (2004) when they state that research has not yet clearly demonstrated which configurations most affect innovation in particular contexts and that the most significant are for future research is in the area of network dynamics and network configurations (Pittaway et al., 2004). Even though the interaction approach provides accurate and useful details about individual structure and process variables (Van de Ven \& Drazin, 1985) it also has certain limitations in studying the relationship between structure and context.

1) The interaction approach obtains mixed results. Correlational studies have shown that the relationships between structure and context are stronger for higher performing organizations than for lower performing organizations, but often the differences are small and not significant as was the case for our first set of hypotheses. 2) Multiplicative interaction terms in regression analysis limit the form of the interaction only to acceleration and deceleration effects, 3) the focus on how single contextual factors affect single structural characteristics and how these pairs of context and structure factors interact to explain performance leads to reductionism (Van de Ven \& Drazin, 1985). Further research could be advanced by employing methodological approaches that allow addressing simultaneously the many contingencies, structural alternatives, and performance criteria that must be considered holistically to understand organization design (Van de Ven \& Drazin, 1985) which may result 
in a clear demonstration of which configuration most affects innovation performance in a particular context.

Furthermore a suggestion for further research is to focus on dyadic relationships. In its present form, the research focuses on network characteristics from the viewpoint of one of the partner organizations in the NPD project. It might be very interesting to also include their counterparts in the NPD project to provide additional insights on the organization of NPD in networks.

In addition, since our sample consisted mostly of companies that developed low and moderately new products, we were only able to detect the effects of these levels of product innovativeness and network characteristics in these companies. Future research may consider gathering additional data in order to have a more evenly spread of products with low, moderate and high innovativeness to examine the effect of product innovativeness and network characteristics on innovation performance. To examine the role of product innovativeness as a control variable for SMEs in a highly regulated sector more data on products with high product innovativeness is needed. Additional data could be gathered in the pharmaceutical sector or in the sector that focuses on the hybrid drug-device combinations.

A final suggestion for future research is a cross-industry study for generalizability of the research findings. As the context of our research was the highly regulated medical devices sector, we expect to find the same findings in other highly regulated sectors. A cross-industry study in multiple highly regulated sectors might shed additional light on the role of product innovativeness in relation to innovation performance when new product characteristics are bounded by regulations. Other highly regulated sectors which might be included in such a study are the biotechnology (Senker, 1991) and commercial space sector (Carayannis \& Samanta Roy, 2000). 


\section{CONCLUDING REMARKS}

We argued that both product innovativeness and SME network characteristics have a direct effect on the innovation performance of SMEs. Using the context of SMEs in the Dutch medical devices sector, we show that the interaction between multiple network characteristics of the SME has a direct positive effect on innovation performance. In addition we find no evidence for a direct effect of product innovativeness on innovation performance in this research context.

The research findings indicate that external collaboration is not merely an act of filling the resource gaps in the organization as a reaction on environmental dynamics, rather the network configuration is a strategic instrument of the SME, that has a direct positive effect on innovation performance which can lead to substantive competitive advantage in the area of new product development

Managers of SMEs in the medical devices sector that aim to achieve high innovation performance, should focus on the organization of the network (i.e. network configuration) that is specifically used for new product development, instead of focusing on the level of product innovativeness of new products. In conclusion, what really counts for achieving high innovation performance for SMEs in the medical devices sector is the way in which network characteristics are combined into a network configuration. 


\section{FIGURE 1}

Integration of the multidimensional framework of Groen et al. (2005) and the Network Dimensions of Nahapiet and Ghoshal (1998)

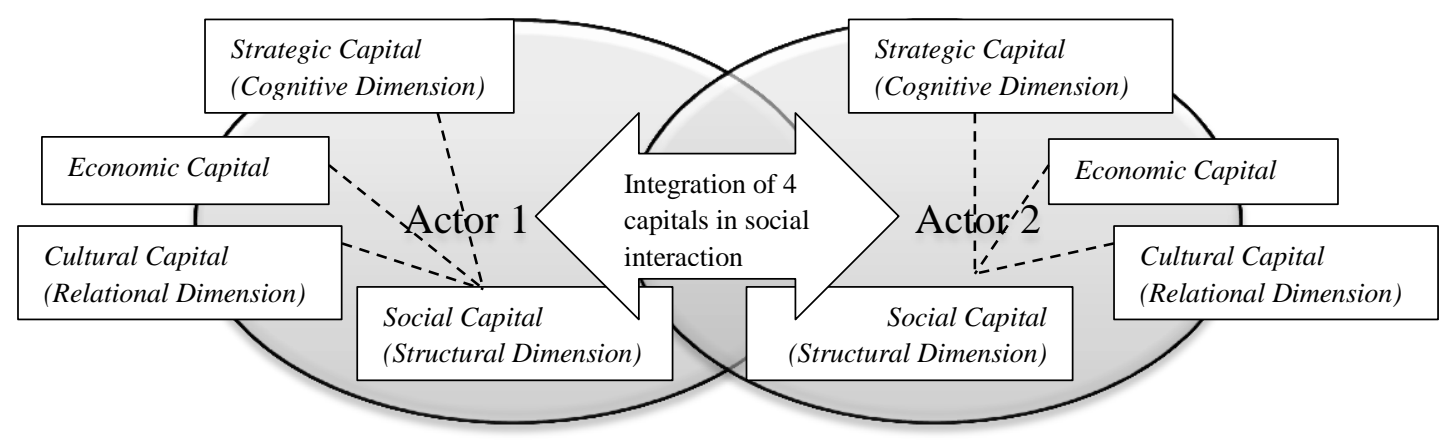

FIGURE 2

Research Model

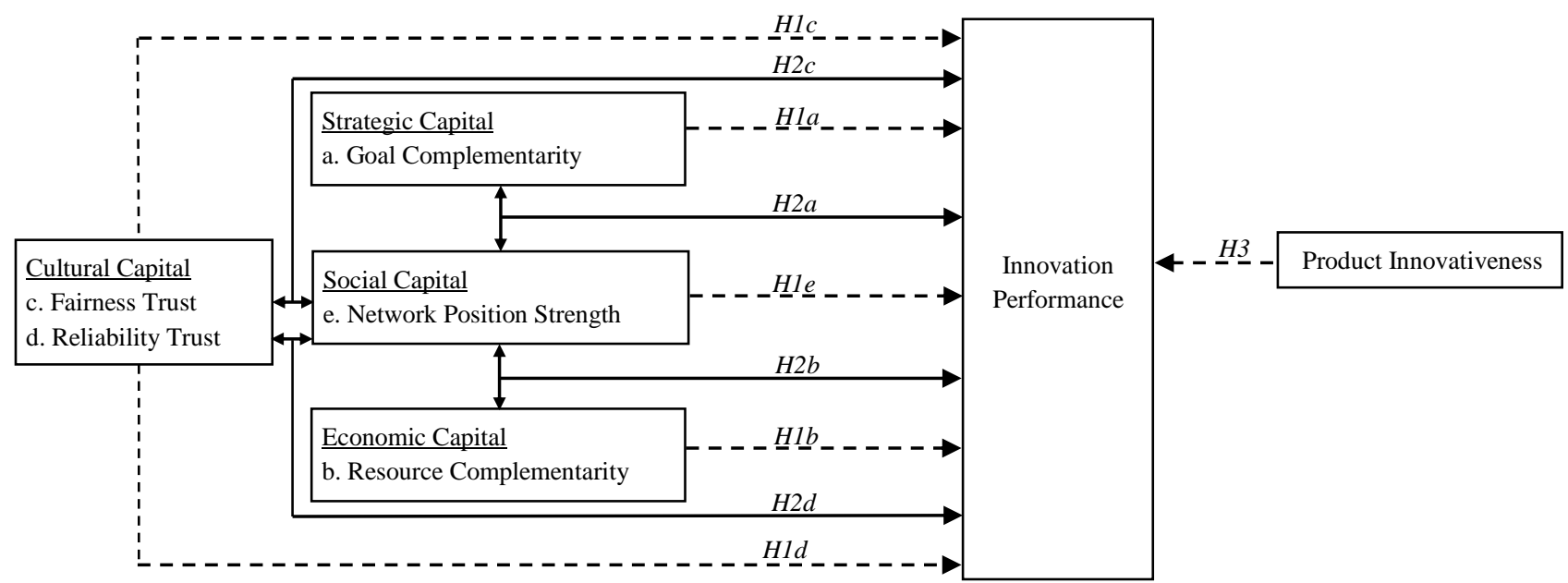


FIGURE 3

Product Innovativeness Types in the Sample

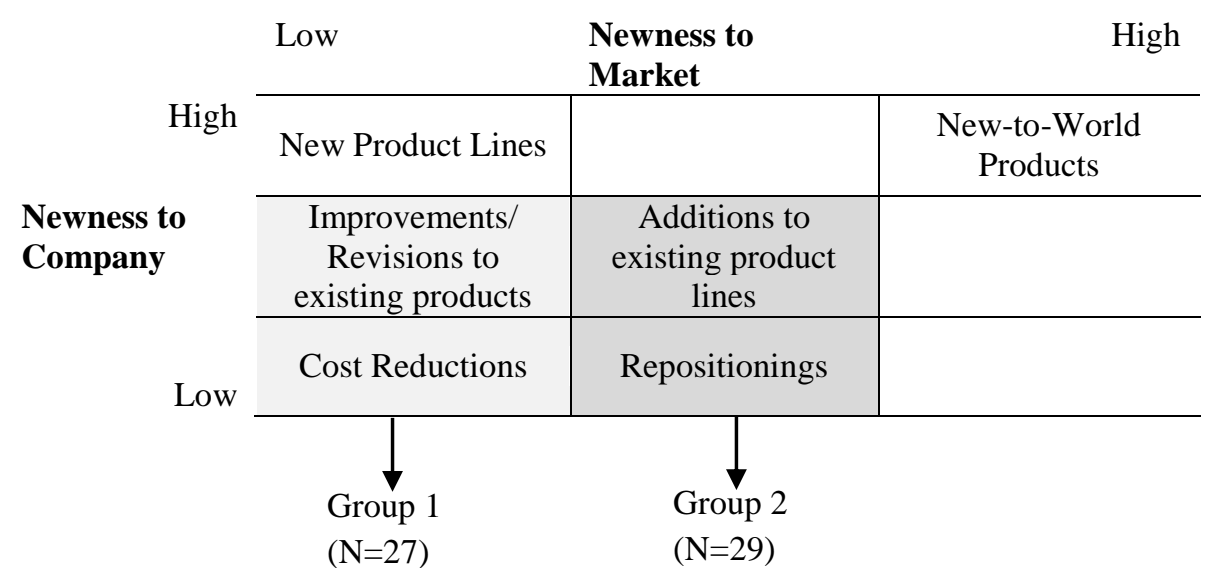

FIGURE 4

Support of the Hypotheses when shifting from low to medium Innovation Performance

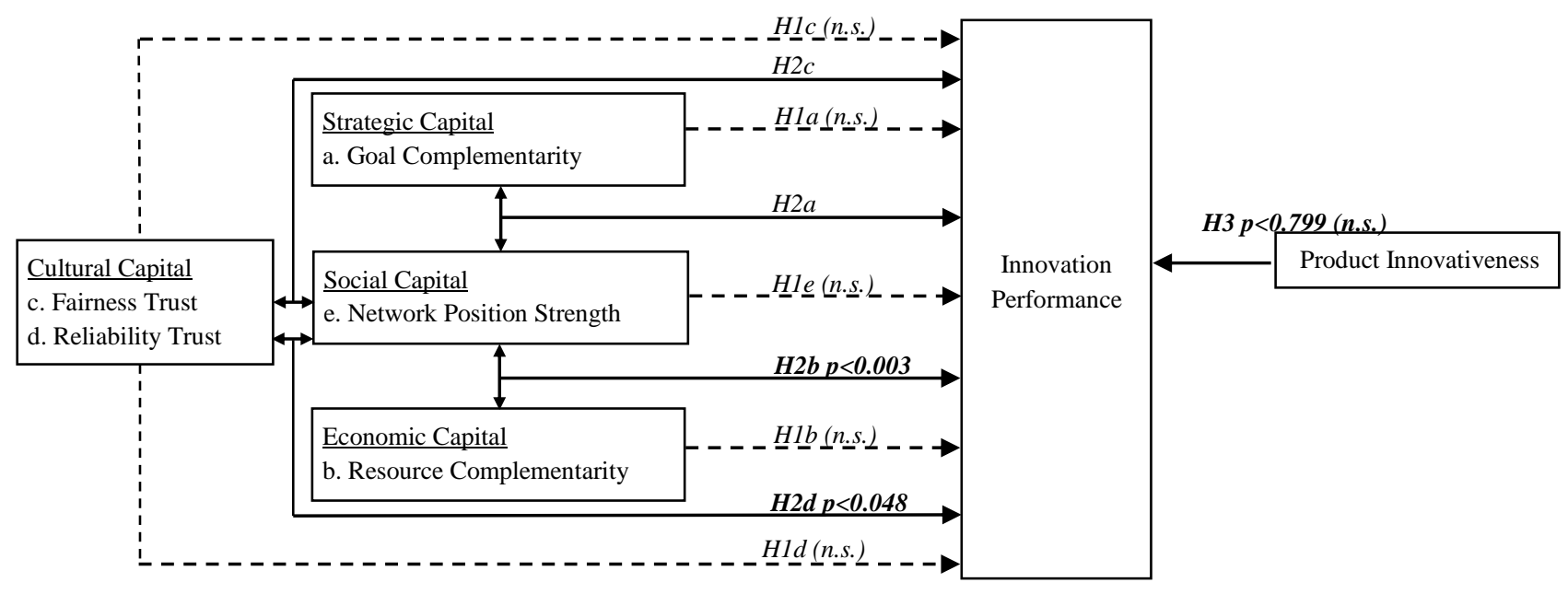

FIGURE 5

Support of the Hypotheses when shifting from low to high Innovation Performance

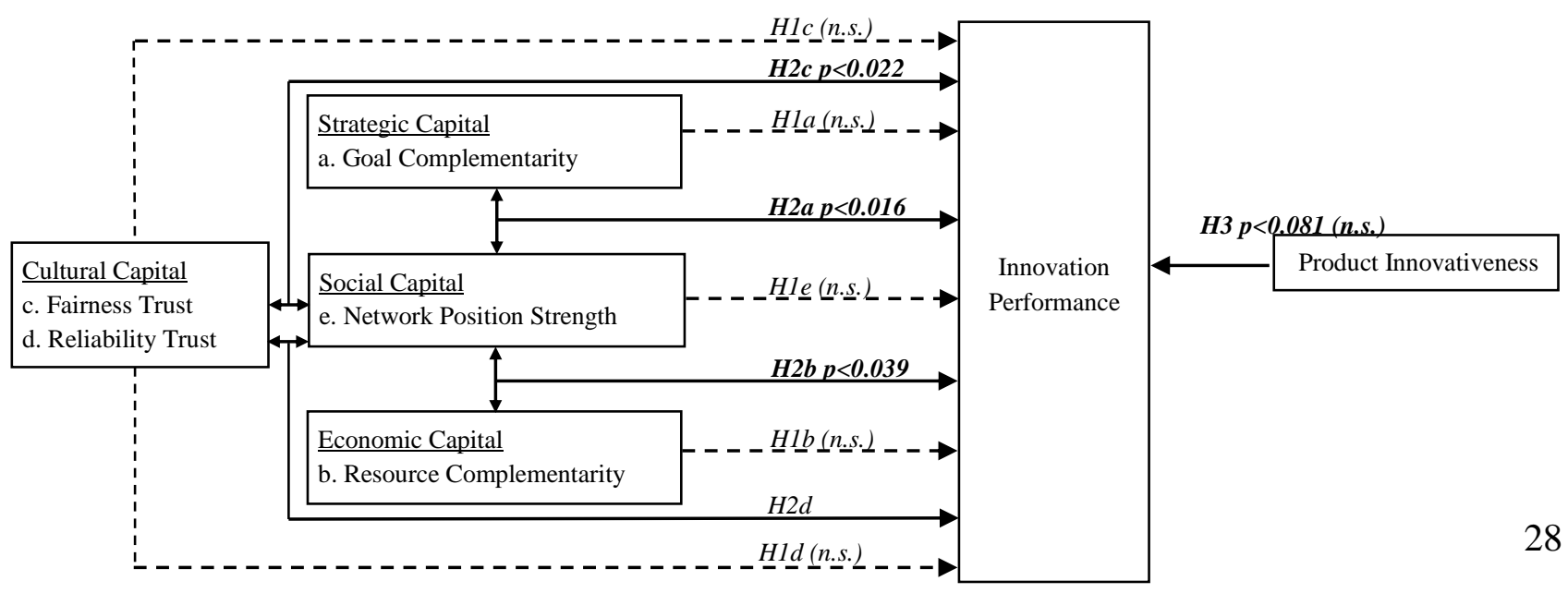


TABLE 1

Response Rate of the Sample

\begin{tabular}{l|l|c|c|c}
\cline { 3 - 4 } \multicolumn{2}{c}{} & Frequency & Percent & $\begin{array}{c}\text { Cumulative } \\
\text { Percent }\end{array}$ \\
\hline \multirow{2}{*}{ Valid } & $\begin{array}{l}\text { filled-in questionnaire } \\
\text { filled-in questionnaire + } \\
\text { interview }\end{array}$ & 13 & 13.4 & 13.4 \\
& withdrawn participation & 37 & 48.5 & $\mathbf{6 1 . 9}$ \\
\cline { 2 - 5 } & Total & 97 & 100.0 & 100.0 \\
\hline
\end{tabular}

TABLE 2

Response Rate of the Population

\begin{tabular}{l|l|c|c|c}
\cline { 3 - 4 } \multicolumn{2}{c}{} & Frequency & Percent & $\begin{array}{c}\text { Cumulative } \\
\text { Percent }\end{array}$ \\
\hline Valid & filled-in questionnaire & 13 & 12.4 & 12.4 \\
& $\begin{array}{l}\text { filled-in questionnaire + } \\
\text { interview }\end{array}$ & 47 & 44.8 & $\mathbf{5 7 . 1}$ \\
withdrawn participation & 37 & 35.2 & 92.4 \\
not interested in & 8 & 7.6 & 100.0 \\
\cline { 2 - 5 } & participation & 105 & 100.0 & \\
\hline
\end{tabular}

TABLE 3

Component Matrix for the Dependent Variable

\begin{tabular}{lc}
\hline & \multicolumn{1}{c}{ Component } \\
\cline { 2 - 2 } & Innovation Performance \\
\hline Q8.1_MarketShare_Objective & .797 \\
Q8.2_Sales_Objective & .876 \\
Q8.3_ReturnAssets_Objective & .897 \\
Q8.4_ReturnInvestment_Objective & .894 \\
Q8.5_Profitability_Objective & .906 \\
\hline Eigenvalue & 3.828 \\
\hline \% Variance explained & 76.56 \\
\hline Cronbach's $\alpha$ & 0.923 \\
\hline \# items & 5 \\
\hline Extraction Method: Principal Component Analysis.
\end{tabular}


TABLE 4

Rotated Component Matrix for the Independent Variable

\begin{tabular}{|c|c|c|c|c|c|}
\hline & \multicolumn{5}{|c|}{ Component } \\
\hline & 1 & 2 & 3 & 4 & 5 \\
\hline & $\begin{array}{c}\text { Resource } \\
\text { Complemen- } \\
\text { tarity } \\
\end{array}$ & $\begin{array}{c}\text { Fairness } \\
\text { Trust }\end{array}$ & $\begin{array}{c}\text { Reliability } \\
\text { Trust } \\
\end{array}$ & $\begin{array}{l}\text { Network } \\
\text { Position } \\
\text { Strenth }\end{array}$ & $\begin{array}{c}\text { Goal } \\
\text { Complemen- } \\
\text { tarity } \\
\end{array}$ \\
\hline Q19.1_CreatedUniqueCapabilities & .807 & & & & \\
\hline Q19.2_TogetherDevelopedKnowledge & .784 & & & & \\
\hline Q19.3_TogetherInvestedInBuildingBusiness & .810 & & & & \\
\hline Q19.4_TogetherInvestedInRelationship & .798 & & & & \\
\hline Q19.5_IfEndedKnowledgeWasted & .735 & & & & \\
\hline Q19.6_IfPartnerSwitchInvestmentsWasted & .836 & & & & \\
\hline Q20.1_ContributeDifferentResources & .683 & & & & .505 \\
\hline Q20.2_ComplementaryStrengths & .590 & .439 & & & \\
\hline Q20.3_SeparateAbilitiesCombined & .695 & .418 & & & \\
\hline Goal_Differences & & & & & .861 \\
\hline Q25.1_TreatYouFairly & & .897 & & & \\
\hline Q25.2_ConfidentialityOfInformation & & .933 & & & \\
\hline Q25.4_Inv_ProfitAtYourExpense & & & .797 & & \\
\hline Q25.5_Inv_CannotCompletelyRelyOnPromises & & & .857 & & \\
\hline Q25.6_Inv_HesitantVagueSpecifications & & & .771 & & \\
\hline Inv_Density & & & & .934 & \\
\hline Ties_Brokered_normalized & & & & .942 & \\
\hline Eigenvalue & 6.39 & 2.16 & 1.95 & 1.47 & 1.01 \\
\hline$\%$ Variance explained & 37.61 & 12.71 & 11.49 & 8.63 & 5.93 \\
\hline Cronbach's $\alpha$ & 0.922 & 0.928 & 0.749 & 0.906 & $\mathrm{X}$ \\
\hline \# items & 9 & 2 & 3 & 2 & 1 \\
\hline
\end{tabular}

TABLE 5

Model Fitting Information

\begin{tabular}{lcccc}
\hline & $\begin{array}{c}\text { Model Fitting } \\
\text { Criteria }\end{array}$ & \multicolumn{2}{c}{ Likelihood Ratio Tests } \\
\cline { 2 - 5 } & $\begin{array}{c}-2 \text { Log } \\
\text { Likelihood }\end{array}$ & Chi-Square & df & Sig. \\
\hline Intercept Only & 96.751 & & & \\
Final & 51.304 & 45.447 & 10 & .000 \\
\hline
\end{tabular}


TABLE 6

Goodness of Fit

\begin{tabular}{lccc}
\hline & Chi-Square & df & Sig. \\
\hline Pearson & 86.834 & 100 & .823 \\
Deviance & 51.304 & 100 & 1.000 \\
\hline
\end{tabular}

TABLE 7

Parameter Estimates

\begin{tabular}{|c|c|c|c|c|c|c|c|c|c|}
\hline \multirow{2}{*}{\multicolumn{2}{|c|}{ FACInnovationPerformance $3 \mathrm{cat}^{\mathrm{a}}$}} & \multirow[b]{2}{*}{$\mathrm{B}$} & \multirow[b]{2}{*}{ Std. Error } & \multirow[b]{2}{*}{ Wald } & \multirow[b]{2}{*}{ df } & \multirow[b]{2}{*}{ Sig. } & \multirow[b]{2}{*}{$\operatorname{Exp}(B)$} & \multicolumn{2}{|c|}{$\begin{array}{l}95 \% \text { Confidence } \\
\text { Interval for } \operatorname{Exp}(B)\end{array}$} \\
\hline & & & & & & & & $\begin{array}{l}\text { Lower } \\
\text { Bound }\end{array}$ & $\begin{array}{l}\text { Upper } \\
\text { Bound }\end{array}$ \\
\hline \multirow[t]{7}{*}{ medium } & Intercept & 2.127 & .723 & 8.657 & 1 & .003 & & & \\
\hline & [Innovativeness 2 cat=1] & -.253 & .997 & .065 & 1 & .799 & .776 & .110 & 5.473 \\
\hline & [Innovativeness 2 cat $=2]$ & $0^{\mathrm{b}}$ & . & . & 0 & . & . & . & . \\
\hline & $\begin{array}{l}\text { FACNetworkPositionStrength * } \\
\text { FACGoalComplementarity }\end{array}$ & -.297 & .810 & .134 & 1 & .714 & .743 & .152 & 3.639 \\
\hline & $\begin{array}{l}\text { FACReliabilityTrust } * \\
\text { FACNetworkPositionStrength }\end{array}$ & 1.875 & .950 & 3.900 & 1 & $.048^{*}$ & 6.523 & 1.014 & 41.955 \\
\hline & $\begin{array}{l}\text { FACResourceComplementarity } \\
* \text { FACNetworkPositionStrength }\end{array}$ & -3.782 & 1.254 & 9.090 & 1 & $.003 * *$ & .023 & .002 & .266 \\
\hline & $\begin{array}{l}\text { FACFairnessTrust * } \\
\text { FACNetworkPositionStrength }\end{array}$ & -1.672 & 1.060 & 2.487 & 1 & .115 & .188 & .024 & 1.501 \\
\hline \multirow[t]{7}{*}{ high } & Intercept & -4.396 & 2.980 & 2.176 & 1 & .140 & & & \\
\hline & [Innovativeness $2 \mathrm{cat}=1]$ & 5.146 & 2.953 & 3.038 & 1 & .081 & 171.783 & .527 & 56016.173 \\
\hline & [Innovativeness 2 cat=2] & $0^{\mathrm{b}}$ & . & . & 0 & . & & . & . \\
\hline & $\begin{array}{l}\text { FACNetworkPositionStrength * } \\
\text { FACGoalComplementarity }\end{array}$ & -3.458 & 1.429 & 5.858 & 1 & $.016^{*}$ & .031 & .002 & .518 \\
\hline & $\begin{array}{l}\text { FACReliabilityTrust } * \\
\text { FACNetworkPositionStrength }\end{array}$ & 1.635 & 1.082 & 2.280 & 1 & .131 & 5.128 & .614 & 42.788 \\
\hline & $\begin{array}{l}\text { FACResourceComplementarity } \\
\text { * FACNetworkPositionStrength }\end{array}$ & -3.126 & 1.516 & 4.249 & 1 & $.039^{*}$ & .044 & .002 & .858 \\
\hline & $\begin{array}{l}\text { FAC FairnessTrust * } \\
\text { FACNetworkPositionStrength }\end{array}$ & -4.135 & 1.808 & 5.234 & 1 & $.022 *$ & .016 & .000 & .553 \\
\hline
\end{tabular}

a. The reference category is: low.

b. This parameter is set to zero because it is redundant.

$$
\begin{aligned}
* \mathrm{p} & <.05 \\
* * \mathrm{p} & <.01
\end{aligned}
$$




\section{REFERENCES}

Afuah, A. 1998. Innovation Management. New York: Oxford University Press.

Ahuja, G. 2000. Collaboration networks, structural holes, and innovation: a longitudinal study. Administrative science quarterly, 45(3): 425-455.

Aldrich, H. E., \& Pfeffer, J. 1976. Environments of organizations. Annual Review of Sociology, 2: 79105.

Atun, R., Shah, S., \& Bosanquet, N. 2002. The medical devices sector: coming out of the shadow. European Business Journal, 14: 63-72.

Becker, W., \& Dietz, J. 2004. R\&D cooperation and innovation activities of firms - evidence for the German manufacturing industry. Research Policy, 33: 209-223.

Biemans, W. G. 1989. Developing innovations within networks: with an application to the Dutch medical equipment industry. Unpublished Doctoral Thesis, University of Eindhoven, Eindhoven.

Booz, Allen, \& Hamilton. 1982. New products management for the 1980s. New York: Booz, Allen and Hamilton, Inc.

Borgatti, S. P., Jones, C., \& Everett, M. G. 1998. Network measures of social capital. Connections, 21(2): 27-36.

Bourgeois III, L. J. 1980. Performance and Consensus. Strategic management journal, 1(3): 227-248.

Branzei, O., \& Thornhill, S. 2006. R\&D networks and innovation capabilities: a context-contingency perspective. Paper presented at the The Academy of Management Conference 2006, Atlanta, Georgia, USA.

Brown, A., Dixon, D., Eatock, J., Meenan, B. J., \& Young, T. 2008. A survey of success factors in new product development in the medical devices industry. Paper presented at the Engineering Management Conference (IEMC), Estoril, Portugal.

Burt, R. S. 1992. Structural holes: the social structure of competition. Cambridge, MA: Harvard University Press.

Capaldo, A. 2007. Network structure and innovation: the leveraging of a dual network as a distinctive relational capability. Strategic management journal, 28: 585-608.

Carayannis, E. G., \& Samanta Roy, R. I. 2000. Davids vs Goliaths in the small satellite industry: the role of technological innovation dynamics in firm competitiveness. Technovation, 20: 287297.

Chang, Y. C. 2003. Benefits of co-operation on innovative performance: evidence from integrated circuits and biotechnology firms in the UK and Taiwan. R\&D Management, 33(4): 425-437.

Child, J. 1972. Organization structure, environment, and performance - the role of strategic choice. Sociology, 6: 1-22.

Commission of the European Communities. 2003. Commission Recommendation of 6 May 2003 Concerning the Definition of Micro, Small and Medium-Sized Enterprises (notified under document number C (2003) 1422) 2003/362/EC., Vol. 46 (L124): 36-42: Official Journal of the European Union.

Danneels, E., \& Kleinschmidt, E. J. 2001. Product innovativeness from the firm's perspective: its dimensions and their relation with project selection and performance. Journal of product innovation management, 18: 357-373.

Deeds, D. L., \& Hill, C. W. L. 1996. Strategic alliances and the rate of new product development: an empirical study of entrepreneurial biotechnology firms. Journal of Business Venturing, 11: 41-55.

Drazin, R., \& Van de Ven, A. H. 1985. Alternative forms of fit in contingency theory. Administrative Science Quarterly, 30: 514-539.

Faems, D., Janssens, M., Madhok, A., \& Van Looy, B. 2008. Toward an integrative perspective on alliance governance: connecting contract design, trust dynamics, and contract application. The Academy of Management Journal, 31(6): 1053-1078. 
Faems, D., VanLooy, B., \& Debackere, K. 2005. Interorganizational collaboration and innovation: toward a portfolio approach. Journal of Product Innovation Management, 22: 238-250.

FDA. 2004. Innovation stagnation: challenge and opportunity on the critical path to new medical products: U.S. Department of Health and Human Service, Food and Drug Administration.

Gadde, L. E., \& Håkansson, H. 1994. The changing role of purchasing: reconsidering three strategic issues. European Journal of Purchasing and Supply Management, 1(1): 27-35.

Galunic, D. C., \& Rodan, S. 1998. Resource recombinations in the firm: knowledge structures and the potential for Schumpeterian innovation. Strategic Management Journal, 19: 1193-1201.

Gemünden, H. G., Ritter, T., \& Heydebreck, P. 1996. Network configuration and innovation success: an empirical analysis in german high-tech industries. International Journal of Research in Marketing, 13: 449-462.

Gilsing, V. A., \& Nooteboom, B. 2005. Density and strength of ties in innovation networks: an analysis of multimedia and biotechnology. European Management Review, 2: 179-197.

Groen, A. J., Wakkee, I. A. M., \& DeWeerd-Nederhof, P. C. 2008. Managing tensions in a high-tech start-up: An innovation journey in social system perspective. International Small Business Journal, 26(1): 57-81.

Gulati, R., \& Sytch, M. 2008. Does familiarity breed trust? Revisiting the antecedents of trust. Managerial and Decision Economics, 29(2-3): 165-190.

Hair, J. F., Anderson, R. E., Tatham, R. L., \& Black, W. C. 1995. Multivariate data analysis: with readings (4th ed.). Upper Saddle River, NJ, USA: Prentice-Hall, Inc.

Håkansson, H. (Ed.). 1987. Industrial technological development: a network approach. London, UK: Croom Helm.

Håkansson, H. 1989. Corporate technological behavior: co-operatoin and networks. London: Routledge.

Hanna, V., \& Walsh, K. 2002. Small firm networks: a successful approach to innovation? $R \& D$ Management, 32(3): 201-207.

Haythornthwaite, C. 1996. Social network analysis: an approach and technique for the study of information exchange. Library and information science research, 18(4): 323-342.

Hillebrand, B., \& Biemans, W. G. 2004. Links between internal and external cooperation in product development: an exploratory study. Journal of product innovation management, 21: 110122.

Hourd, P. C., \& Williams, D. J. 2008. Results from an exploratory study to identify the factors that contribute to success for UK medical device small-and mediumsized enterprises. Journal of Engineering in Medicine, Part $\mathrm{H}: 222:$ 717-735.

Inkpen, A. C., \& Tsang, E. W. K. 2005. Social capital, networks, and knowledge transfer. The Academy of Management Review, 30(1): 148-165.

Kaplan, A. V., Baim, D. S., Smith, J. J., Feigal, D. A., Simons, M., Jefferys, D., Fogarty, T. J., Kuntz, R. E., \& Leon, M. B. 2004. Medical device development: from prototype to regulatory approval. Circulation, 109: 3068-3072.

Karlsson, C., \& Olsson, O. 1998. Product innovation in small and large enterprises. Small Business Economics, 10: 31-46.

Kaufmann, A., \& Tödtling, F. 2002. How effective is innovation support for SMEs? An analysis of the region of upper Austria. Technovation, 22(3): 147-159.

Kleinschmidt, E. J., \& Cooper, R. G. 1991. The impact of product innovativeness on performance. Journal of product innovation management, 8(4): 240-252.

Kline, P. 2000. A psychometrics primer: Free Association Books

Lambe, C. J., Spekman, R., \& Hunt, S. D. 2002. Alliance competence, resources and alliance success: conceptualization, measurement, and initial test. Journal of the Academy of Marketing Science, 30(2): 141-158. 
Langerak, F., \& Hultink, E. J. 2006. The impact of product innovativeness on the link between development speed and new product profitability. Journal of product innovation management, 23: 203-214.

Leana, C. R., \& Van Buren III, H. J. 1999. Organizational social capital and employment practices. The Academy of Management Review, 24(3): 538-555.

MacPherson, A. 1997. A comparison of within-firm and external sourcecs of product innovation. Growth and Change, 28: 289-308.

Miller, D., \& Friesen, P. H. 1982. Innovation in conservative and entrepreneurial firms: two models of strategic momentum. Strategic management journal, 3(1): 1-25.

Millson, M. R., \& Wilemon, D. 2000. Managing Innovation in medical devices. International journal of healthcare technology and management, 2(5/6): 425-455.

Nahapiet, J., \& Ghoshal, S. 1997. Social capital, intellectual capital and the creation of value in firms. Academy of Management Best Paper Proceedings: 35-39.

Nahapiet, J., \& Ghoshal, S. 1998. Social capital, intellectual capital, and the organizational advantage. The Academy of Management Review, 23(2): 242-266.

Nieto, M. J., \& Santamaría, L. 2010. Technological collaboration: Bridging the innovation gap between small and large firms. Journal of Small Business Management, 48(1): 44-69.

Nooteboom, B. 1994. Innovation and Diffusion in small firms: theory and evidence. Small Business Economics, 6: 327-347.

Oerlemans, L. A. G., Meeus, M. T. H., \& Boekema, F. W. M. 1998. Do networks matter for innovation? The usefulness of the economic network approach in analysing innovation. Tijdschrift voor economische en sociale geografie, 89(3): 298-309.

Parsons, T. 1937. The structure of social action. New York: The Free Press.

Parsons, T. 1964. The social system (new.ed. ed.). New York: The Free Press.

Penrose, E. T. 1959. The theory of the growth of the firm. New York: John Wiley.

Pett, M. A., Lackey, N. R., \& Sullivan, J. J. 2003. Making sense of factor analysis: The use of factor analysis for instrument development in health care research. Thousand Oaks, USA: Sage Publications, Inc.

Pittaway, L., Robertson, M., Munir, K., Denyer, D., \& Neely, A. 2004. Networking and innovation: a systematic review of the evidence. International Journal of Management Review, 5/6(3\&4): 137-168.

Powell, W. W., Koput, K. W., \& Smith-Doerr, L. 1996. Interorganizational collaboration and the locus of innovation: networks of learning in biotechnology. Administrative science quarterly, 41(1): 116-145.

Prabhakar, S. 2006. Medical devices + collaboration = innovation. Advanced Materials \& Processes, 164(10): 46 .

Pullen, A. J. J., Groen, A. J., Fisscher, O. A. M., \& De Weerd-Nederhof, P. C. 2010. Measuring the network-innovation performance in SMEs: The development of a questionnaire. Paper presented at the R\&D Management Conference 2010, Manchester, UK.

Ritter, T., \& Gemünden, H. G. 2003. Network competence: its impact on innovation success and its antecedents. Journal of Business Research, 56:745-755.

Ritter, T., \& Gemünden, H. G. 2004. The impact of a company's business strategy on its technological competence, network competence and innovation success. Journal of Business Research, 57: 548-556.

Rochford, L., \& Rudelius, W. 1997. New product development process: stages and successes in the medical products industry. Industrial Marketing Management, 26: 67-84.

Rogers, M. 2004. Networks, firm size and innovation. Small Business Economics, 22: 141-153.

Rothwell, R. 1991. External networking and innovation in small and medium-sized manufacturing firms in Europe. Technovation, 11(2): 93-112.

Salman, N., \& Saives, A. L. 2005. Indirect networks: an intangible resource for biotechnology innovation. R\&D Management, 35(2): 203-215. 
Salomo, S., Strecker, N., \& Talke, K. 2007. Innovation strategy - investigating the performance effects of innovativeness, familiarity, driver of innovation, and innovation field orientation. Paper presented at the 14th International Product Development Management Conference, Porto, Portugal.

Salomo, S., Talke, K., \& Strecker, N. 2008. Innovation field orientation an its effect on innovativeness and firm performance. Journal of product innovation management, 25: 560576.

Senker, J. 1991. National systems of innovation, organization, and learning in industrial biotechnology. Technovation, 16(5): 219-229.

Shaw, B. 1998. Innovation and new product development in the UK medical equipment industry. International Journal of Technology Management, 15(3-5): 433-445.

Song, X. M., \& Montoya-Weiss, M. M. 1998. Critical development activities for really new versus incremental products. Journal of product innovation management, 15: 124-135.

Szymanski, D. M., Kroff, M. W., \& Troy, L. C. 2007. Innovativeness and new product success: insights from the cumulative evidence. Journal of the academy of marketing science, 35:35-52.

Teece, D. J. 1989. Inter-organizational requirements of the innovation process. Managerial and Decision Economics, 10(Special Issue: Competitiveness, Technology and Productivity): 3542 .

Tichy, N. M., Tushman, M. L., \& Fombrun, C. 1979. Social network analysis for organizations. The Academy of Management Review, 4(4): 507-519.

Van de Ven, A. H., \& Drazin, R. 1985. The concept of fit in contingency theory. In L. L. Cummings, \& B. M. Staw (Eds.), Research in Organizational Behavior, Vol. 7: 333-365. Greenwich, CT: JAI Press.

Wasserman, S., \& Faust, K. 1994. Social network analysis: methods and applications. New York: Cambridge University Press.

Wheelwright, S. C., \& Clark, K. B. 1992. Creating project plans to focus product development. Harvard Business Review, 70(2): 70-82.

Zaheer, A., McEvily, B., \& Perrone, V. 1998. Does Trust Matter? Exploring the Effects of Interorganizational and Interpersonal Trust on Performance. Organization Science, 9(2): 141-159. 